\section{The vexed question of race-based admission to medical school}

To the Editor: The issue raised by the Editor regarding selection criteria for medical school admission ${ }^{1}$ resonates well with my own views on this thorny issue. I believe that race-based criteria are counter-productive, and tend to reinforce the entitlement attitude, a post-apartheid tendency which remains unaddressed in our infant democracy today.

We all need to endeavour to transcend the racially charged context in which we were brought up and educated. My formative years were in a racially segregated town, Mthatha, long before apartheid appeared on the scene. My brief stay in Cape Town from exile (cf. my autobiography From Exile to Exile) showed me that racial tensions still exist between the different ethnic groups. As we seek to overcome this legacy, we should nevertheless not excuse our democratic government of abetting racism with the excuse that they are seeking to reverse the effects of apartheid.

The issue of selection of medical students is not only a South African problem. In the UK, doctors are trying to address this issue (sifuna isitya emnyameni). The selection criteria in the UK have only in part been academic, but have historically favoured those from the better-off families in leafy suburbs, and from the best schools. Selection also favoured males (Victorian-era influence?). But things are changing, with more female students and those from disadvantaged backgrounds being selected. Broadly speaking, I would say that capitalist countries (e.g. the USA) have tended to prioritise attributes of privilege, while social democratic countries emphasised social attributes (previous experience of serving in a caring role, political awareness about the role of poverty in disease causation, mature students who are more likely to be empathetic in caring roles).

In South Africa, we should perhaps consider the kind of doctors our medical schools aim to produce. I would think that we want to produce:

- doctors who combine empathy with competence, serving as servants, and not as lords, in managing common and unspectacular disorders that impact on the physical, psychological and social well-being of ordinary people

- 'high fliers' who will enter postgraduate training to become experts and who will, it is to be hoped, combine empathy with competence in managing challenging and sometimes rare disorders that impact on the physical, psychological and social well-being of ordinary people.

I would like to suggest the following selection criteria:

- personal attributes (such as age and gender)

- academic criteria: level of academic achievement, and/or the potential to be academically successful

- social service experience: past experiences serving in a caring role; awareness of global health issues in South Africa; sense of maturity and cultural sensitivity

- markers of deprivation: students from schools with poor science teaching and standards; students from dysfunctional/poor families; and physically disabled or challenged students with the motivation and potential to succeed in the study of medicine.

I believe that such criteria would go a long way towards addressing past imbalances. They would ensure that white students from poor families with demonstrable empathic qualities are not excluded. Indeed, this could help to give affirmative action a favourable social face and do away with racial undertones.

\author{
E M Mankazana \\ General practitioner \\ London, UK \\ mxomank@doctors.org.uk \\ 1. Ncayiyana DJ. The vexed question of race-based admission to medical school. S Afr Med \\ 2012;102(4):193.
}

